DOI 10.5216/ia.v45i3.64518

\title{
IMPRENSA PEDAGÓGICA: O INFORMATIVO NOSSO RUMONA OFICIALIZAÇÃO DE UMA NOVA REPRESENTAÇÃO DE MEMÓRIA EM MARINGÁ (1984 - 1987)
}

\author{
Daniella Domingues Alvarenga MARQues \\ ELAINE RODRIGUES \\ Universidade Estadual de Maringá (UEM), Maringá, Paraná, Brasil
}

\begin{abstract}
Resumo: O artigo tem como tema a Imprensa Pedagógica. Como problema, analisou-se como e porque o informativo Nosso Rumo, produzido pela Secretaria de Educação de Maringá, propôs-se a divulgar o Projeto Memória. O recorte possui como marco inicial o ano de 1984 e estende-se até 1987. Justifica-se este recorte, pois, durante a década de 1980, as reivindicações acerca da retomada da democracia no país eram bastante presentes, a publicação desse informativo figura entre essas ações, ainda que sua abrangência tenha sido localizada. Descreve-se o informativo, com destaque para o Projeto Memória, tendo como elemento norteador a resposta ao questionamento: Por que o informativo Nosso Rumo priorizou a circulação do Projeto Memória? Os procedimentos metodológicos foram: coleta, classificação e análise dos conteúdos do informativo.

Palavras-Chave: História da Educação. Informativo Nosso Rumo. Imprensa Pedagógica. Projeto Memória.
\end{abstract}

\section{INTRODUÇÃO}

O que são impressos pedagógicos? livros didáticos, manuais escolares, imprensa periódica especializada em educação, bibliotecas escolares, coleções dirigidas a professores, dentre outros. Os impressos são objeto e não só fonte de investigação. Objeto com duplo sentido: como dispositivo de normatização pedagógica e como amparo material para as práticas escolares. A materialidade desses objetos passa a ser o suporte do questionário que orienta o investigador no estudo das ações que se formalizam nos seus usos escolares. Chartier $(2002$, p. 62) diz que "não existe texto fora do suporte que o dá a ler", que não há compreensão de um escrito que não dependa das formas por meio das quais ele chega ao seu leitor.

A Imprensa especializada em educação e ensino ou a Imprensa Pedagógica, compreendida como possibilidade documental, como fonte de pesquisa, tem ajudado a construir, conhecer e escrever a História da Educação de um dado lugar, em um dado tempo (CERTEAU, 1982). O trabalho de pesquisa que se apropria dos Impressos Educacionais não é propriamente uma novidade entre os Historiadores da Educação, mas também não pode ser caracterizado como algo comum. A materialidade do objeto impresso, em sua configuração textual e tipográfica, e outras fontes dantes desconsideradas, tornaram-se visíveis aos historiadores, em particular aos historiadores da educação, como um desdobramento das transformações provindas de debates 
internacionais produzidos, inicialmente, no campo da história (FOUCAULT, 2005, LE GOFF, 2003, CERTEAU, 1982).

Na escrita historiográfica da educação, os jornais e as revistas têm recebido dos pesquisadores dedicação expressiva quando se trata daqueles que circularam junto ao público escolar. A pesquisa com o uso da Imprensa Pedagógica como fonte e objeto tem se tornado frequente. A análise dos editoriais, cartas ao leitor e demais seções que compõem o impresso são, cada vez mais, consideradas fundamentais para a História da Educação. Entretanto, adverte-se que é necessário ser consciente quanto ao que esse tipo de material pode fornecer e sobre seus limites, pois, segundo Lopes \& Galvão (2001, p. 87), as fontes "não são espelho, nem da realidade vista/vivida, nem de nenhuma verdade; são apenas a representação que a surpresa, a emoção, ou os preconceitos e até injunções e conveniências políticas de um tempo e lugar específicos, Ihe permitiram construir e contar". Na mesma direção, a reflexão de Fernandes (2012, p. 32) alerta: "Há que se ter cuidado para não cair na tentação de achar que ali está uma espécie de História verdadeira, ligada a uma falsa ou ingênua ideia do que realmente aconteceu ".

É importante ressaltar que a Imprensa Pedagógica, em seus princípios formuladores, é aquela que veicula interesses de "alguém" (uma instituição, por exemplo) para um grupo de pessoas, com propósitos previamente definidos. O objetivo é que a mensagem escolhida para circular seja apropriada para o seu leitor, pois não há imparcialidade, ao contrário, o impresso divulga aspirações, apresenta necessidades e especificidades de um grupo social e os antagonismos pertinentes a toda dinâmica educacional (BASTOS \& CATANI, 1997; GONÇALVES NETO, 2007, BICCAS, 2008; FERNANDES, 2012).

É perceptível que os estudos direcionados à compreensão do contexto de produção, circulação e impactos relacionados à imprensa especializada em educação e ensino avançaram muito no Brasil, ao menos em termos quantitativos, principalmente depois dos anos de 1990, tornando-se flagrante o número de revistas, jornais e outros periódicos publicados com regularidade e interesses educacionais. Entretanto, a produção de pesquisa, de caráter acadêmico, que apresenta como lócus o Paraná, e elege a Imprensa Pedagógica - que aqui se circulou ou que aqui se produziu - como fonte e objeto de análise, ainda é pouco expressiva.

Um dos temas de pesquisa que apresentou ascensão com a consolidação do uso da Nova História Cultural como paradigma analítico, no Brasil, foi a Imprensa Pedagógica, considerada pela corrente teórica como um material importante para o estudo de uma época, devido à divulgação de informações que faz circular sobre a organização, direcionamento e sistematização de uma instituição, grupo específico ou governo. Por meio da análise de impresso pedagógico, podem ser vislumbrados os direcionamentos, as políticas normativas e as propostas para a educação no processo da investigação das práticas que se formalizam nos espaços escolares. Conforme Nunes, (1992), Carvalho $(1998,2000)$ e Lopes \& Galvão (2001, p. 82), alguns temas "receberam permissão" para serem elencados como tema e ou objeto de pesquisa, dentre eles, "o livro escolar, o caderno de aluno, o mobiliário, o uniforme e a imprensa pedagógica, assim como outros tantos renegados pela historiografia da educação em seu formato mais tradicional".

Para Pensavento (2003, p. 39), a Nova História Cultural propiciou mudanças epistemológicas e metodológicas que asseguraram o estabelecimento de "[...] novos olhares e formas de pensar o mundo e o homem", isto é, um novo modo de investigação 
que mudou a maneira de compreender e de escrever a história a partir dos estudos sobre as culturas populares. Essa nova linha de pesquisa tratou de "[...] pensar a cultura como um conjunto de significados partilhados e construídos pelos homens para explicar o mundo" (PENSAVENTO, 2005, p. 15).

A Nova História Cultural colaborou para colocar em discussão o fazer historiográfico e a repensar os limites das fronteiras de pesquisa, preconizando que o "[...] conhecimento do passado é uma coisa em progresso, que incessantemente se transforma e aperfeiçoa" (BLOCH, 2001, p. 75). A história vista como uma área de produção do saber que compreende as ações humanas por intermédio de teorias, fontes, vestígios e indícios.

Dessa forma, a Imprensa Pedagógica, compreendida como um acervo documental, possibilita a interpretação da realidade e permite o avanço na compreensão de fatores que consolidam um grupo de uma determinada época, bem como a melhor compreensão sobre os desdobramentos produzidos na historiografia da educação brasileira.

O objetivo da Imprensa Pedagógica é divulgar discursos, veicular e principiar as concepções de diferentes sujeitos, favorecendo diálogos e a especificidade representativa dos grupos participantes. Para Nóvoa (1997, p. 30), o Impresso Pedagógico é um dos meios de comunicação que apresenta os "interesses e as problemáticas no campo educacional de um determinado período histórico". Nesse sentido, o trabalho com esse tipo de fonte apresenta os direcionamentos e as normativas determinadas do sistema educacional de uma sociedade, evidencia as políticas públicas, diretrizes, as práticas pedagógicas e a cultura escolar.

Além disso, possibilita problematizar preocupações sociais e concepções ideológicas efetivadas e, ao investigador, problematizar o passado, a fim de construir novas representações e desconstruir uma visão a priori consolidada. Este artigo objetiva descrever os aspectos que a Secretaria Municipal de Educação (SEDUC) de Maringá colocou em circulação por meio do Impresso Pedagógico Nosso Rumo sobre a educação maringaense na década de 1980. Em destaque, os aspectos de como e do porquê priorizou-se, no impresso, a divulgação do Projeto Memória.

Justifica-se a escolha do impresso Nosso Rumo, como fonte, pelo fato do informativo caracterizar-se como um dos meios efetivos e oficiais de comunicação, escolhido para vincular ideais, propostas, concepções teóricas e pedagógicas, destinadas à escola pública e à comunidade escolar. Em suma, divulgava e orientava o que deveria ser ensinado.

O estudo contará com a descrição do informativo Nosso Rumo, impresso pedagógico que veiculava reflexões, análises educacionais e sociais, por meio dos textos editoriais e projetos pedagógicos. Em seguida, serão descritos os principais esforços que a SEDUC buscou consolidar para a educação maringaense. No último tópico, será apresentado o Projeto Memória, em destaque, sobre os aspectos priorizados na veiculação do projeto.

O caminho metodológico adotado para o desenvolvimento do trabalho e a adequação aos objetivos propostos foram realizados mediante procedimentos historiográficos: coleta, classificação e análise dos conteúdos do informativo Nosso Rumo, bem como consultas em livros, periódicos e artigos. Machado \& Rodrigues (2017, p. 255) afirmam que o "[...] desafio do historiador da educação é descobrir o tempo das certezas normativas, por certo, tudo é interrogação". Faz parte do ofício do historiador lidar com as fontes, pois, de acordo com Le Goff (2003, p. 106), “[...] sem documento não há história". 
Dessa forma, é necessário que o pesquisador eleja técnicas e procedimentos metodológicos de forma rigorosa, priorize os aspectos de classificação, categorização e regulação do documento que será analisado como fonte. Para Le Goff $(2003$, p. 497), todo documento deve passar por uma desconstrução, a fim de identificar as montagens de sua produção.

Nesse sentido, quando o historiador seleciona um documento, precisa constituir uma problemática central, a qual direciona e concede condições de elaborar e analisar questionamentos gestados ao longo da pesquisa. Posto isso, a fonte é o principal elemento na produção historiográfica, pois é por meio dela que o pesquisador tem condições de desempenhar seu ofício. No caso deste artigo, o informativo Nosso Rumo.

\section{DESCRIÇÃO: O INFORMATIVO NOSSO RUMO}

O informativo Nosso Rumo é um Impresso Pedagógico que possui como público-alvo a comunidade educacional, seus objetivos apresentam a normatização pedagógica e suporte material, os quais possibilitam a efetivação das práticas e dos usos escolares. Nesse sentido, este artigo intenta observar se o impresso, como estratégia, buscou evidenciar e fortalecer os interesses da SEDUC para a educação de Maringá e, caso tenha sido essa a finalidade, como se deu a publicação.

O informativo foi produzido na cidade de Maringá entre os anos de 1984 e 1987 , sendo sua primeira publicação em junho/julho de 1984, durante a gestão do prefeito Said Felício Ferreira $(1983-1988)^{1}$. O impresso vinculava informações e saberes do trabalho desenvolvido pela equipe administrativa da SEDUC, da gestão pedagógica e do trabalho dos professores nas escolas municipais. Ao longo dos anos de produção mencionados, o informativo Nosso Rumo teve 28 edições, contudo não seguiu uma padronização e periodização na construção de seus exemplares, ou seja, as edições não possuíam temas, assuntos e objetivos definidos, aspectos seguidos pela maioria da Imprensa Pedagógica especializada.

A SEDUC não delimitou no informativo uma organicidade estrutural única. A formatação e a configuração, bem como as implicações políticas e os relatos de formação e desenvolvimento da prática pedagógica, foram apresentadas e ordenadas de formas distintas ao longo das publicações.

As edições apresentavam textos e reflexões sobre aspectos teóricos, metodológicos, políticos e pedagógicos. Destacavam-se os debates, os direcionamentos e as normatizações sobre como a educação deveria ser gestada nas escolas públicas, sendo expostos na primeira página das edições.

O informativo possuía peculiaridades de um jornal, pois, desde as primeiras produções, mesmo sem seguir uma padronização, cumpria alguns critérios, tais como: chamadas, divisões por seções que separavam os conteúdos, a divulgação de informações sobre formação continuada e práticas pedagógicas que deveriam ser apropriadas pelos professores nas escolas públicas.

As informações no impresso também contemplavam as exposições de trabalhos e atividades, as apresentações dos alunos, os encaminhamentos e os resultados dos projetos elaborados pela SEDUC e executados nas escolas municipais. Veiculavam notícias sobre assuntos relacionados ao entretenimento local da cidade, como 
atividades culturais, casamentos e nascimentos de filhos de funcionários e professores, que atuavam na área da educação.

Segundo Martins e Luca (2006, p. 11), a imprensa não se limita a "[...] apresentar o que aconteceu, mas seleciona, ordena, estrutura e narra, de uma determinada forma, aquilo que elege como fato digno de chegar até o público". O trabalho do historiador com o documento se dá no labor, no diálogo e no contato direto com a sua fonte e objeto.

O Impresso Pedagógico como meio de representação é, para este trabalho, capaz de orientar, de forma intelectual e moral, os indivíduos no meio em que circula, portanto, é utilizado para auxiliar e guiar os profissionais da educação, um parâmetro para os processos escolares.

De acordo com Chartier (1990), o indivíduo busca registrar sua cultura, hábitos e tradições. Desse modo, a cada época, utiliza-se o possível para produzir memória e delimitar seu poder. Reconstruir o passado parte de percepções interpretativas. Para o autor, a categoria "representação", diante da escrita da história, deve ser produzida perante os fatos construídos por intermédio das lentes que as observam, analisam e constroem as interpretações.

[...] as representações do mundo social são sempre determinadas pelos interesses dos grupos que as forjam. [...]As percepções do social não são de forma alguma discursos neutros: produzem estratégias e práticas que tendem a impor uma autoridade à custa de outros, legitimando assim suas escolhas e condutas. [...]. Por isso as representações colocam-se sempre no campo da concorrência e se enunciam em termos de poder e dominação. As lutas de representações têm tanta importância como as lutas econômicas para compreender os mecanismos pelos quais um grupo impõe ou tenta impor a sua concepção do mundo social, os valores que são os seus e o seu domínio (CHARTIER, 1991, p. 17).

Dessa forma, a compreensão das representações de um determinado período histórico é fundamental para a contextualização de uma sociedade, uma vez que propicia suporte para entender o passado histórico por meio da reconstrução, do novo olhar e dos sentidos produzidos pelo historiador ao priorizar a criticidade frente aos sentidos construídos a partir do conteúdo da fonte.

A classificação dos números do informativo Nosso Rumo foi definida pelas publicações produzidas entre os anos de 1984 e 1987, material que se encontrava devidamente organizado de maneira sequencial no Patrimônio Histórico na cidade de Maringá. O trabalho priorizou a desconstrução da linearidade por considerar relevante a ordenação conforme os conteúdos, as análises, constatações representativas destacadas no impresso pela Secretaria de Educação e conteúdos relacionados à produção de memória, educação e democracia, que são temáticas predominantes encontradas na catalogação, no agrupamento e na sistematização de sua problematização central. Tal procedimento contribuiu para a produção do impresso e do Projeto Memória, modelo pedagógico organizado constituído à educação maringaense.

Diante dessa perspectiva, o informativo Nosso Rumo e o Projeto Memória são relevantes para entender a educação maringaense nos primeiros anos da década de 1980, pois fornecem dados sobre esse período que buscou estabelecer um modelo educacional e escrever a história do município de Maringá, que será destacado no próximo tópico. 


\section{MARINGÁ: UMA CIDADE MODELO, E SUA EDUCAÇÃO}

Na década de 1980, a memória e a história apresentada na região estavam sob o domínio dos relatos, textos e artigos produzidos pela Companhia de Melhoramentos do Norte do Paraná (CMNP), empresa privada, colonizadora de Maringá, que ditava as regras e as condições de permanência dos indivíduos, além disso, possuía o apoio do Governo do Paraná, suporte para a execução do projeto da cidade, promovendo facilidades para a instalação de empresas e afirmando que a cidade era lucrativa para qualquer tipo de negócio.

De acordo com Cordovil (2010, p. 582), a cidade de Maringá foi previamente planejada e obedeceu às diretrizes de um plano urbanístico que priorizou a preservação de áreas verdes e a vegetação nativa. Além disso, as ruas, praças e avenidas respeitaram as características topográficas da região. O autor destaca que o projeto da cidade foi vinculado à propaganda da CMNP, apresentava técnicas urbanísticas modernas, aprovadas por arquitetos, urbanistas e engenheiros, que seguiam as tendências mundiais de arquitetura.

Ainda para o autor, a Companhia trabalhou para o desenvolvimento da cidade e ofereceu elementos estéticos modernos, uma cidade convidativa para morar e trabalhar, além de próspera às negociações.

Segundo Luz (1997, p. 115), as condições econômicas e as terras férteis no norte do Paraná contribuíram para o sucesso da empreiteira, pois garantiam a chegada de pessoas dispostas a comprar, trabalhar e morar na estrutura oferecida na cidade maringaense. Desse modo, os esforços da iniciativa privada contribuíram para as vendas dos terrenos do município.

A CMNP promoveu, portanto, uma cidade modelo, acolhedora e atraente para viver. Assim, a empresa foi estratégica em suas ações, divulgou aspectos estruturais e lucrativos a fim de angariar novos compradores de terras para a região maringaense.

Campos (1999, p. 329), em seu estudo sobre a cidade de Maringá, evidencia que a leitura oficial, que diz respeito à história da cidade até a década de 1980, era contada com base em uma versão, um olhar, uma única forma de relatar as memórias. Divulgavase a história de uma "[...] cidade planejada, sem males, uma utopia que até hoje seduz os defensores do planejamento urbano" (CAMPOS, 1999, p. 329).

Para Campos (1999), há uma discrepância em algumas informações subsidiadas pela Companhia, por exemplo: mesmo com todo desenvolvimento apresentado pela empresa colonizadora, os moradores, vindos do campo e de outras regiões do Brasil, não possuíam qualificação para trabalhar nos ofícios que a cidade oferecia, especialmente nas áreas da indústria e do comércio. Desqualificados para o mercado de trabalho urbano, homens e mulheres pobres, e com pouca escolarização, contrastavam com o progresso de Maringá. Essa situação resultou em marginalidade, pois "[...] os marmanjos, vagabundos e vadios, ou seja, aqueles que não tinham trabalho, eram impossibilitados de habitar os espaços da malha urbana" (CAMPOS, 1999, p. 321).

A fim de conter a proliferação dessa classe, os dirigentes da cidade instituíram métodos de disciplinarização e de moralização dos costumes, além de uma maior ação de censura e violência. Campos (1999) evidencia que os indivíduos eram desprovidos de características para o convívio social, como: trabalhar, morar, cultivar o corpo e o espírito, conforme os bons costumes e padrões vigentes da época. 
A educação na cidade era seletiva, a maioria dos filhos da classe trabalhadora não tinha acesso à escola ou não permanecia nela, pois eles eram "eliminados", especialmente aqueles com menor poder aquisitivo. A exclusão resultava na configuração social precária e violenta. Muitas famílias que chegavam à cidade não tinham acesso às condições básicas e mínimas de subsistência.

Em resumo, identificou-se que o crescimento da população sem trabalho da cidade, devido ao deslocamento das pessoas do campo para o meio urbano, gerou o aumento da criminalidade e insegurança. É importante salientar que toda a nação brasileira, entre as décadas de 1960 e 1980, estava sob o regime ditatorial com base na repressão e violência. Naquele momento, os dirigentes militares buscaram conter a marginalidade, os pensamentos e ideais contrários aos ditados por eles.

O governo militar, como afirmamos anteriormente, estabelecia dispositivos e padrões de controle social, econômico e político aos cidadãos. Com isso, foi gerada insegurança na população, pois asseguravam que havia uma ameaça de instaurar um governo comunista no país.

O medo e o "fantasma" do comunismo contribuíram para o estabelecimento de ações estratégicas, dentre elas: implantar um modelo de governo totalitário que mobilizava a sociedade civil de cima para baixo, estabelecendo na nação uma organicidade social obediente e controlada. Os métodos ditatoriais utilizados eram de caráter compulsório de contenção política, cultural e social.

Segundo Rodrigues (2012, p. 29), o objetivo era estabelecer "[...] estratégias e táticas que o medo, forma de governabilidade da população, fosse personificado como um saber de governo, um saber que antecedia todos os processos de bem-estar da população". Nesse sentido, é possível perceber que o processo histórico de Maringá foi subordinado a um âmbito mais amplo que constitui a História da Educação no Brasil. Em 1980, com base nas diretrizes da educação nacional, a cidade iniciou o processo de nuclearização da rede municipal, em que foi estabelecida a reorganização das escolas rurais e urbanas sob a responsabilidade do munícipio. De acordo com Amaro e Rodrigues (1999), um dos principais projetos da nuclearização era resolver o problema de infraestrutura, conservação, manutenção e reformas nas escolas.

Algumas metas foram destacadas para a organização burocrática do ensino, como a elaboração do calendário escolar, o estabelecimento da carga horária diária de quatro horas, treinamento do corpo docente e técnico-administrativo, apoio educacional e organização direta e indireta nas escolas por intermédio da equipe de orientação pedagógica da SEDUC. Em 1980, Maringá já possuía sete núcleos, cada um correspondia a uma escola com quatro ou mais salas de aula, além das salas da direção, supervisão, orientação e secretaria. Na época, as escolas também contavam com ambulatório odontológico.

Amaro e Rodrigues (1999, p. 383) explicitam que a equipe que assumiu a SEDUC em 1983, encontrou uma "infraestrutura propícia às novas reivindicações para o ensino, especialmente quanto ao direito de escolarização e à permanência da população em idade escolar". Para os autores, "[...] implementar as melhorias no nível de qualidade do ensino e permanência se tornou a meta principal", assim como os direcionamentos de novas práticas e políticas pedagógicas.

A secretaria elaborou projetos de acesso à escolarização que assegurassem a todas as crianças o direito de frequentar e permanecer nas escolas. Dentre as ações, a secretaria ficou responsável por reuniões mensais e quinzenais na rede municipal e priorizou treinamentos para os professores atuarem em sala de aula. Os professores eram assessorados por área de atuação, orientados em grupos acerca da elaboração dos 
planejamentos e dos conteúdos que seriam ensinados em sala de aula (AMARO; RODRIGUES, 1999, p. 383).

É importante ressaltar que a SEDUC de Maringá atendia aos primeiros níveis da educação básica, desde a pré-escola até as $8^{a}$ séries ${ }^{2}$, além das coordenações de núcleo comum de todo sistema municipal de ensino. Os encontros traçavam as diretrizes e os planejamentos pedagógicos que deveriam ser desenvolvidos nas escolas. Outra ação instituída pela secretaria foi a contratação de professores com a carga horária semanal de 25 horas, entretanto, em um dia na semana, não lhes eram atribuídas aulas, o tempo era destinado à elaboração de planejamento, às reuniões e aos cursos pedagógicos. Essas estratégias possibilitavam ao profissional da educação ser assertivo em sua atuação no processo de democratização. Foram estabelecidos novos caminhos e encaminhamentos pedagógicos.

Uma educação com base em princípios democráticos, que atendesse às manifestações da prática social e dos interesses de todos, além de uma escola que promovesse a circulação de propostas e ideais para toda sociedade. Uma educação específica que operava para atingir fins políticos e sociais amplamente. Assim, na década de 1980, a educação de Maringá estava alinhada às orientações e diretrizes do Estado do Paraná e do Brasil.

A SEDUC, em Maringá, trabalhou para que o projeto estadual e nacional de educação fosse executado, planejou e estabeleceu estratégias, uma delas foi a criação e veiculação do informativo Nosso Rumo, Impresso Pedagógico utilizado para divulgar um novo modelo de ensino que estava sendo proposto e almejado.

\section{OFICIALIZAÇÃO DE UMA NOVA MEMÓRIA MARINGAENSE}

O Projeto Memória foi idealizado e promovido pela SEDUC em parceria com a Secretaria de Turismo e Cultura de Maringá. Possuía dois objetivos: o primeiro era escrever a história de Maringá através de estudos e pesquisas com os moradores da cidade; o segundo era produzir material didático condizente com a realidade das crianças, uma vez que seria utilizado como recurso pedagógico nas escolas municipais de $1^{\text {a }}$ a $4^{\text {a }}$ série.

O projeto buscou dados, objetos e documentos para construir, sob um novo enfoque, a história do município de Maringá. O intuito era compreender a trajetória do processo histórico e "[...] favorecer a integração social das crianças" (MARINGÁ, 1984a, p. 1). A $2^{\text {a }}$ edição do informativo Nosso Rumo (MARINGÁ, 1984b, p. 2) explicita que o projeto foi oficialmente lançado no dia 28 agosto de 1984, no Anfiteatro da Biblioteca Municipal Bento Munhoz da Rocha Neto, contudo, foi divulgado, na primeira edição do informativo, com a finalidade de propiciar aos professores e alunos das escolas municipais, um ensino que priorizasse a realidade e o contexto social da população maringaense.

Nas edições do informativo, a SEDUC detalhou o planejamento, a elaboração e o desenvolvimento das atividades exercidas pela equipe de historiadores, assim como a atuação dos professores na execução de práticas pedagógicas coerentes com os objetivos da secretaria na implementação do projeto.

De acordo com Maringá (1984e, p. 4), o projeto piloto iniciou-se no distrito de Floriano que, naquele momento, possuía maior concentração fixa de moradores, porém, no mesmo ano, estendeu-se a Maringá. O projeto buscou proporcionar às comunidades 
urbanas, rurais e periféricas informações não somente sobre a história de Maringá, mas também sobre as cidades que eram distritos, como Floriano e Iguatemi.

A preocupação era proporcionar uma "[...] educação que ultrapasse a simples reprodução de conceitos e fórmulas" (MARINGÁ, 1984e, p. 4). Assim, a SEDUC "[...] constatou a necessidade de realizar pesquisas e estudos para produzir um inventário histórico e cultural de Maringá" (MARINGÁ, 1984e, p. 4), que resgatasse a consciência histórica com base na valorização da realidade histórica do maringaense.

A SEDUC afirmava que o Projeto Memória deveria ser considerado memória efetiva na cidade de Maringá, pois apresentava forma e conteúdo. Segundo Maringá (1985f, p. 2), a equipe havia resgatado, com o auxílio dos moradores, documentos que apresentavam informações sobre a constituição da população maringaense. Os documentos já haviam sido separados e organizados em arquivos e o cadastramento dos pioneiros já estava quase finalizado. De acordo com o informativo, o trabalho objetivava o "[...] resgate da "memória viva" (MARINGÁ, 1985f, p. 2).

O informativo Maringá (1986a, p. 3) divulgou que a equipe iria dinamizar suas atividades, além de informar sobre o encontro promovido pelas Secretarias de Educação, Cultura e Turismo de Maringá com a equipe do Patrimônio Histórico de Curitiba. Nesse encontro, avaliou-se a possibilidade de criação de uma lei municipal para o tombamento histórico da cidade. O intuito era realizar o registro do patrimônio histórico de Maringá com base em uma legislação específica e oficial do Estado, ou seja, registrar oficialmente o que era de valor para a comunidade, assim como preservar suas referências, marcas e marcos da história da sociedade maringaense.

Na mesma edição, o impresso explicita a participação de duas integrantes do Projeto Memória em um programa de estágio oferecido na Universidade de Campinas (Unicamp). O estágio tinha o objetivo de favorecer o aperfeiçoamento das participantes em técnicas historiográficas, como gerenciamento das fontes primárias, desenvolvimento e execução de métodos e procedimentos historiográficos, os quais deveriam priorizar as análises e a veracidade da investigação historiográfica. Trabalho rigoroso, fruto de sistematizações complexas e minuciosas.

Maringá (1986d, p. 4) apresenta a criação do Centro de Documentação em Maringá, espaço que seria utilizado para guardar documentos, fotos, vídeos, discos e objetos históricos, local no qual os pesquisadores iriam coletar e selecionar as principais informações sobre a fundação e povoamento do município. Um espaço de trabalho para os historiadores do Projeto Memória, incumbidos de classificar, catalogar e organizar documentos e objetos de forma sistematizada.

O informativo divulgava que o Projeto Memória buscava conservar e preservar os documentos que eram adquiridos pelos cidadãos e empresas maringaenses, visava também coletar dados e objetos do processo de colonização e urbanização de Maringá.

Maringá (1986d, p. 4) relata, sobre o Projeto Museu de Rua, intitulado Retratos do lugar de uma gente, um museu sem paredes, portas ou janelas, montado em pontos estratégicos da cidade, que esse museu exibiria fotos, documentos, textos, jornais e objetos coletados, que contavam a história do povo e do munícipio de Maringá.

Na 23a edição do informativo Nosso Rumo (MARINGÁ, 1987b, p. 3), a SEDUC destacou um dos trabalhos desenvolvidos nas escolas municipais, segundo a orientação e edição dos professores de História, em parceria com o Projeto Memória, sendo organizado uma pesquisa com foco na história da cidade. A equipe do projeto, com auxílio dos docentes, direcionou-se até as escolas e apresentou aos alunos fotos e slides que registravam fatos importantes sobre a cidade. A estratégia contribuiu para o enriquecimento do conhecimento de 235 alunos da rede municipal de ensino, os quais 
aprenderam sobre a história dos pioneiros de Maringá, estudo que é apresentado no informativo intitulado Conhecendo Nossa História.

Na mesma edição, foi divulgado outro trabalho realizado na Escola Municipal Delfim Moreira, pelo professor de geografia da instituição, com os alunos da $6^{a}$ série, sobre os migrantes e imigrantes na região de Maringá.

\begin{abstract}
Com objetivo de fomentar nas crianças uma atitude de curiosidade, observação crítica diante da realidade, às $6^{\text {a }}$ séries, ao estudar a população mundial e do Brasil, pesquisaram através de entrevistas, o motivo da vinda de imigrantes nas localidades em que moram. $O$ estudo obedeceu às seguintes etapas: $1^{\circ}$ estudo dirigido com auxílio de Atlas e livros didáticos, $2^{\circ}$ pesquisa de campo (entrevistas), $3^{\circ}$ tabulação de entrevistas, $4^{\circ}$ conclusões. Dentre as conclusões do trabalho "População Mundial e do Brasil registramos o que se refere aos Migrantes e Imigrantes feitas pelos alunos da Escola Delfim Moreira (MARINGÁ, 1987b, p. 3).
\end{abstract}

De acordo com o impresso, o estudo promoveu uma atividade dirigida de campo, com entrevistas, pesquisas em materiais didáticos, elaboração de questionários, tabulação das entrevistas e registro de conclusões. É importante ressaltar que esse trabalho foi realizado em todas as escolas municipais com os alunos da $6^{\mathrm{a}}$ série.

O impresso também explicita as práticas pedagógicas realizadas pelos alunos, por exemplo: entrevistas com migrantes vindos do estado de São Paulo devido à propaganda da CMNP que divulgava a região dizendo que nela havia melhores condições de vida; entrevistas que os alunos fizeram com imigrantes portugueses, japoneses, italianos, alemães e argentinos sobre os motivos que os levaram a virem para o Brasil, como a $2^{\circ}$ Guerra Mundial, casamento, busca por uma melhor qualidade de vida e conselho de parentes. Ressaltamos que os dois relatos de entrevistas são de uma única escola, entretanto o impresso informa que todos os alunos da rede realizaram tais entrevistas, somando um total de 182 alunos e 65 pessoas entrevistadas (MARINGÁ, 1987b, p. 2).

A $27^{a}$ edição do impresso Nosso Rumo (MARINGÁ, 1987b, p. 2) explicitou ainda, que a equipe do Projeto Memória, a qual iniciava o trabalho de resgate iconográfico da memória arquitetônica de Maringá, levantou dados sobre as primeiras edificações da cidade na região do Maringá Velho, local onde foram feitas as primeiras construções da cidade.

\footnotetext{
A execução de um trabalho dessa natureza, faz-se no caso de Maringá dentro de um caráter de urgência, pois com a velocidade extremada com que vem acontecendo o crescimento da cidade, tanto na verticalização quanto na horizontalização, um dos primeiros elementos condenados à extinção é o espaço físico (edificações) (MARINGÁ, 1987f, p. 4).
}

O principal instrumento adotado pela equipe no processo foi a fotográfica, recurso que, segundo o impresso, possibilitava identificar os marcos históricos. Desse modo, o Projeto Memória foi idealizado para construir as memórias da cidade de Maringá e contou não apenas com o empenho das Secretarias de Educação, Cultura e 
Turismo, mas com o empenho significativo dos profissionais da educação na elaboração de projetos escolares e dos próprios moradores maringaenses.

O informativo Nosso Rumo (MARINGÁ, 1987f, p. 4) afirma que as pesquisas e os estudos veiculados nas escolas municipais visavam conscientizar os alunos a participarem ativamente do Projeto Memória. Estratégias de estudo, como as entrevistas de campo com a população, enriqueciam a proposta de trabalho da equipe da secretaria e do projeto, na medida em que os docentes instruíam os educandos a observarem a História não como uma construção individual, mas, sim, como algo participativo e cooperativo.

\section{CONSIDERAÇÕES FINAIS}

O informativo Nosso Rumo, impresso pedagógico, fonte de pesquisa para este artigo, foi posto em circulação entre os anos de 1984 e 1987, pela SEDUC de Maringá, e teve como público-alvo os professores, equipe administrativa escolar, alunos, pais e a comunidade, e buscou abranger e inserir todos os indivíduos no contexto escolar, tornando-os ativos nos direcionamentos no processo de ensino-aprendizagem, bem como na formação do cidadão maringaense.

O informativo Nosso Rumo foi um dos meios de comunicação que a secretaria utilizou para veicular suas ideias e projetos, instrumento no qual circularam as orientações e objetivos da recém-formada equipe administrativa do Departamento de Educação municipal, no ano de 1983. Veículo de divulgação de novas propostas para a educação maringaense, difundia modos de pensar e agir, portou mensagens selecionadas que circularam em um lugar, para um público em um período histórico.

As propostas do informativo, por meio do Projeto Memória, apresentavam, em sua formatação, elementos de cunho formativo e normativo, que possibilitavam compreender como a SEDUC empreendeu esforços para produzir um novo modelo de cidadão, tendo como suporte o ensino e o espaço escolar.

O intuito do artigo foi verificar como e o porquê o informativo Nosso Rumo, produzido pela Secretaria de Educação de Maringá, priorizou a veiculação do Projeto Memória em suas edições. $\mathrm{O}$ artigo descreveu o contexto histórico e as concepções de memória que a Secretaria intentava oficializar no município.

A secretaria articulava ideias e apresentava, no impresso, reflexões sobre o modo como a educação deveria ser norteada e praticada nas escolas municipais. Em relação à concepção de memória, constatou-se que a memória possui, como princípio, o poder de evocar fatos que ocorreram, a fim de repeti-los no grupo em que foi produzida ao longo do tempo. A memória, como ato de trazer ao presente as lembranças, ou seja, de estímulo à percepção do passado que precisa ser preservado para chegar ao presente, é utilizada como elemento que auxilia na reestruturação e reorganização dos indivíduos.

Dessa forma, uma sociedade que não utiliza a memória é condicionada a não produzir uma identidade cultural e social, sendo afetada e condicionada ao declínio. Por isso, a importância de os membros de uma sociedade terem referências, valores morais, éticos e sociais constituídos por aqueles que efetivaram a história de seu povo. A memória identificada no impresso, a partir do Projeto Memória, buscou recuperar e preservar sua constituição, por meio dos documentos, objetos e relatos apresentados pelos pioneiros e moradores maringaenses. A intenção foi escrever uma história com base na realidade, nas vivências e experiências e nas memórias compartilhadas, que são vistas como representativas para todos os indivíduos. 
A secretaria divulgava frequentemente os objetos e como deveria ser produzida a história da cidade. Nesse sentido, a produção da história e memória apresentada pelo Projeto Memória demonstra que a SEDUC procurou implementar aspectos de democratização e estava alinhada a eles, pois afirmava que o ensino deveria ser cooperativo, participativo e que valorizasse o conhecimento prévio e a história de vida dos alunos, relacionando-os aos conhecimentos científicos produzidos e acumulados ao longo da humanidade, a fim de promover o pensamento crítico, conscientizando as crianças de sua condição humana e histórica. Para a secretaria, esse modelo de ensino concederia protagonismo ao aluno no processo de construção de seu conhecimento.

A SEDUC considerava a escola um espaço político, que tinha condições de promover a formação integral de seus alunos e da comunidade, entretanto, os professores e suas práticas pedagógicas tinham de estar alinhados à luta por uma educação inclusiva e de qualidade, baseada em um ensino crítico e reflexivo. Este estudo contribuiu para que se tornassem conhecidos os debates no campo da educação na década de 1980.

O Projeto Memória foi veiculado nas escolas municipais com o objetivo de difundir concepções e teve como suporte as propostas de práticas pedagógicas que regulariam a constituição social da cidade. Os alunos estudavam, realizavam pesquisas e trabalhos referente à história da fundação e do povoamento de Maringá. Os encaminhamentos do Projeto Memória direcionavam as crianças a serem conscientes de sua condição histórica e social, o que poderia ajudar nas tomadas de decisão, discernir os aspectos da vida humana e interpretar o mundo.

O direcionamento do Projeto Memória era fazer com que os alunos fossem estimulados a desenvolver a consciência crítica, comprometidos com a construção e o dinamismo da sociedade, transformando-se em sujeitos da história e não meros reprodutores. Desse modo, a educação deveria debruçar-se no processo de formação humana com base na dinâmica de vida, do trabalho, da cultura, das tradições e das relações do ser humano em sociedade, levando em conta que tais movimentos não são fixos, mas mutáveis, movidos por constantes transformações que formam e moldam identidades, culturas e pessoas.

Por intermédio do Projeto Memória, a Secretaria de Educação viabilizou uma nova narrativa, um novo discurso para a formação da criança, como também priorizou escrever uma história significativa, compartilhada e representativa para todos, o que foi intencional, pois direcionou o olhar do leitor ao impresso Nosso Rumo para objetivos pré-definidos.

A discussão em torno da análise do Projeto Memória propiciou compreender que a escrita da história e da memória está em constante mudança, uma vez que as pessoas interpretam os elementos da sociedade de modo distintos umas das outras. $\mathrm{O}$ esforço da SEDUC em reconstruir uma história, com base na realidade cultural e social dos moradores maringaenses, é descrita na maior parte das edições do impresso pedagógico Nosso Rumo.

A memória que a secretaria buscou instituir, por meio da educação, teve como suporte os princípios democráticos e a ideia de que a escola era um espaço político e tinha a função de instrumentalizar, sistematizar e cooperar com a construção de um novo modelo de sociedade. A secretaria foi estratégica e atuou baseada em seus ideais para veicular, normatizar e oficializar a memória e a história de Maringá. Contudo, 
futuras pesquisas podem responder outras indagações, a partir de novos olhares e de novas problematizações por meio do informativo Nosso Rumo.

O mérito, por assim definir, dos estudos realizados, que agora toma a forma de artigo, encontra-se na própria caracterização do campo de pesquisa, um espaço fronteiriço que se sustenta por meio do diálogo entre os vários campos das humanas. $\mathrm{A}$ pesquisa e o ensino das humanidades se desdobram e se especificam na constituição de campos disciplinares, reconhecidos e construídos por suas comunidades interpretativas. A História da Educação aí se encaixa, com elementos multidisciplinares constitutivos de suas especificidades.

Artigo recebido em: 18/07/2020

Aprovado para publicação em: 13/10/2020

PEDAGOGICAL PRESS: THE NEWSLETTER NOSSO RUMO (OUR COURSE) IN THE OFFICIALIZATION OF A NEW REPRESENTATION OF MEMORY IN MARINGÁ (1984 - 1987)

ABSTRACT: The present article is about the Pedagogical Press. As a problem, it was analyzed how and why the Nosso Rumo (Our Course) newsletter produced by Maringá Department of Education released the "Memória Project". The time frame has 1984 as its starting point and extends to the year 1987. This cut is justified because, during the 1980s, a new social claim was designed, based on social movements. The general objective describes the newsletter, with emphasis on the "Memória Project", and answers: how and why the printed matter understood as Pedagogical Press prioritized the circulation of the "Memória Project". The methodological paths were historiographic procedures: collection, classification and analysis of the contents of the newsletter. The aim is to collaborate to fill gaps in the history of Maringá education.

KEYWORDS: History of Education. Nosso Rumo Newsletter. Pedagogical Press. Memory Project.

PRENSA PEDAGÓGICA: EL BOLETÍN NOSSO RUMO (NUESTRO CURSO) EN LA OFICIALIZACIÓN DE UNA NUEVA REPRESENTACIÓN DE MEMORIA EN MARINGÁ (1984 - 1987)

RESUMEN: El artículo trata sobre la prensa pedagógica. Como problema, se analizó cómo y por qué el boletín Nosso Rumo (Nuestro Curso) producido por el Departamento de Educación de Maringá lanzó el Proyecto Memoria. El marco temporal tiene a 1984 como punto de partida y se extiende hasta el año 1987. Este corte está justificado, porque durante la década de 1980, se diseñó un nuevo reclamo social, basado en los movimientos sociales. El objetivo general describe el boletín, con énfasis en el Proyecto Memoria, y respuende: cómo y por qué el material impreso entendido como Prensa Pedagógica priorizó la circulación del Proyecto Memoria. Las rutas metodológicas fueron los procedimientos historiográficos: recopilación, clasificación y análisis de los contenidos del boletín. El objetivo es colaborar para llenar los vacíos en la historia de la educación de Maringá.

PALABRAS-CLAVE: Historia de la educación. Boletín de noticias Nosso Rumo. Prensa pedagógica. Proyecto de memoria. 
NOTAS

${ }^{1}$ Prefeito Said Felício Ferreira (1983 - 1988), paulista de nascimento, Said formou-se em medicina na Universidade Federal do Paraná, em Curitiba. Prefeito de Maringá, foi eleito em 1982 e administrou a cidade entre 1983 e 1988 e de 1993 a 1996

${ }^{2}$ No ano de 2005, foi aprovada uma lei pelo Congresso, sancionada pelo governo do Presidente Luiz Inácio Lula da Silva, a qual prevê que a criança com seis anos deve estar no primeiro ano do Ensino Fundamental e não mais na Educação Infantil. A duração obrigatória do Ensino Fundamental também foi ampliada de oito para nove anos pelo projeto de Lei $n^{\circ} 3.675 / 04$, transformado na Lei Ordinária n 11274/2006.

\section{REFERÊNCIAS}

BASTOS \& Maria Helena, CATANI, Denice Bárbara \&. Apresentação. In: CATANI, Denice Bárbara, BASTOS Maria Helena Câmara (Orgs). Educação em Revista - A Imprensa Periódica e a História da Educação. São Paulo, Escrituras, 1997.

BLOCH, M. Apologia da História ou o ofício do historiador. Trad. de Lilia Moritz Schwarcz. Rio de Janeiro: Jorge Zahar, 2001.

CAMPOS, P. F. S. Moralizando o pobre: vadios, baderneiros e loucos na "cidade tecnicamente planejada para ser bela e sem problemas". In: DIAS, R. B.; GONÇALVES, J. H. R (Orgs.). Maringá e o norte do Paraná. Maringá: EDUEM, 1999, p. 315-330.

CARVALHO, Marta M. C. de. A Escola e a República. São Paulo, Brasiliense, 1989. (col. Tudo é história).

CARVALHO, Marta M.C. de. Reformas da Instrução Pública na década de 1920. In: FARIA FILHO, L. M. e LOPES, E.T. VEIGA, C.G.(orgs.). In:500Anos de Educação no Brasil. Belo Horizonte: Autêntica, 2000.

CERTEAU, Michel de. A escrita da história. Trad. de Maria de Lourdes Menezes; Revisão Técnica [de] Arno Vogel. Rio de Janeiro: Forense Universitária 1982. p.65 - 119.

CHARTIER, R. A história cultural entre práticas e representações. Rio de Janeiro: Bertrand Brasil/Lisboa: Difel, 1990.

CHARTIER, R. O mundo como representação. Estudo, São Paulo, v. 5, n. 11, abr. 1991.

CHARTIER, Roger. Os desafios da escrita. Trad. de Fúlvia M. L. Moretto. São Paulo: Ed. UNESP, 2002.

CORDOVIL, F. C. S. A Aventura Planejada: engenharia e urbanismo na construção de Maringá - 1947 a 1982. 2010. 636f. Tese (Doutorado em Arquitetura e Urbanismo) Escola de Engenharia de São Carlos, Universidade de São Paulo, São Carlos, 2010. 
FERNANDES, Ana Lúcia C. A construção do conhecimento pedagógico: análise comparada de revistas de educação e ensino Brasil - Portugal (1880 - 1930). Colecção Textos Universitários em Ciências Sociais e Humanas. Lisboa: Fundação Calouste Gulbenkian/Fundação para a Ciência e Tecnologia, 2012.

FOUCAULT, Michel. A arqueologia do saber. $7^{\mathrm{a}}$ ed. Trad. Luiz Felipe Baeta Neves. Rio de Janeio: Forense Universitária, 2005.

GONÇALVES NETO, Wenceslau. Pulsões culturais no início do século XX: grêmios literários, conferências, teatro e música em Uberabinha, MG, 1908 - 1920. In: SCHELBAUER, Analete Regina \& ARAÚJO, José Carlos de Souza. (org.) História da Educação pela imprensa. Campinas, SP: Alínea, 2007.

LE GOFF, Jacques. História. In: LE GOFF, Jacques. História e memória. Trad. de Bernardo Leitão. São Paulo: Campinas, Editora da UNICAMP, 2003. p. 17 - 171.

LOPES, Eliane Marta Teixeira \& Galvão, Ana Maria de Oliveira. História da Educação. Rio de Janeiro: DP\&A, 2001.

LUZ, F. O Fenômeno urbano numa zona pioneira: Maringá. Maringá: Prefeitura Municipal, 1997.

MACHADO, M. C. G. ; RODRIGUES, ELAINE. Conversas sobre fontes. In: José Gonçalves Gondra, Maria Cristina Gomes Machado, Regina Helena Silva Simões. (Org.). História da educação, matrizes interpretativas e internacionalização. 1ed.,Vitória/ES: EDUFES, 2017 , v. 1, p. 253-271

MARINGÁ (PR). Secretaria de Educação Municipal. Nosso Rumo. Maringá: Secretaria de Educação Municipal, 1. ed., 1984a, p. 1.

MARINGÁ (PR). Secretaria de Educação Municipal. Nosso Rumo. Maringá: Secretaria de Educação Municipal, 11. ed., 1985f, p. 1.

MARINGÁ (PR). Secretaria de Educação Municipal. Nosso Rumo. Maringá: Secretaria de Educação Municipal, 14. ed., 1986a, p. 1.

MARINGÁ (PR). Secretaria de Educação Municipal. Nosso Rumo. Maringá: Secretaria de Educação Municipal, 17. ed., 1986d, p. 3.

MARINGÁ (PR). Secretaria de Educação Municipal. Nosso Rumo. Maringá: Secretaria de Educação Municipal, 2. ed., 1984b, p. 1.

MARINGÁ (PR). Secretaria de Educação Municipal. Nosso Rumo. Maringá: Secretaria de Educação Municipal, 25. ed., 1987b, p. 3.

MARINGÁ (PR). Secretaria de Educação Municipal. Nosso Rumo. Maringá: Secretaria de Educação Municipal, 25. ed., 1987d, p. 4.

MARINGÁ (PR). Secretaria de Educação Municipal. Nosso Rumo. Maringá: Secretaria de Educação Municipal, 27. ed., 1987f, p. 4. 
MARINGÁ (PR). Secretaria de Educação Municipal. Nosso Rumo. Maringá: Secretaria de Educação Municipal, 5. ed., 1984e, p. 2.

MARO, H. S.; RODRIGUES, I. C. Educação Municipal em Maringá: Uma história em meio século. In: DIAS, R. B, GONÇALVES, J. H. R (Orgs.). Maringá e o norte do Paraná. Maringá: EDUEM, 1999, p. 315-330.

MARTINS, A. L; LUCA, T. R. Imprensa e cidade. São Paulo: Editora UNESP, 2006. NÓVOA, A. A imprensa de educação e ensino. In: CATANI, D. B.; BASTOS, M. H. C. (Orgs.). Educação em revista: a imprensa periódica e a história da educação. São Paulo: Escrituras, 1997, p. 11-31.

NUNES, Clarice e CARVALHO, Marta Maria. Historiografia da educação e fontes. Cadernos ANPED, Porto Alegre, n.5, setembro de 1993.

NUNES, Clarice e CARVALHO, Marta Maria. Historiografia da educação e fontes. Cadernos ANPED, Porto Alegre, n.5, setembro de 1993.

NUNES, Clarice. O Passado sempre presente. São Paulo: Cortez, 1992.

PENSAVENTO, S. J. Cultura e representações. Revista do programa de pós-graduação em História. Porto Alegre: UFRGS, Porto Alegre, v. 13, n. 23/24, p.45- 58, jan./dez. 2006.

PENSAVENTO, S. J. Cultura e representações: uma trajetória. Revista do programa de pós-graduação em História. Porto Alegre: UFRGS, Porto Alegre, v. 13, n. 23/24, p.45- 58, jan./dez. 2006.

RODRIGUES, E. A re(invenção) da educação no Paraná: apropriação do discurso democrático (1980 - 1990). Maringá: EDUEM, 2012.

Daniella Domingues Alvarenga Marques: Graduada em Pedagogia pela Universidade Estadual de Maringá, Pós Graduada em Gestão e Coordenação Escolar, Pós Graduada em Psicopedagogia Institucional e Mestre em Educação pela Universidade Estadual de Maringá. Possui experiência na área de Educação, com ênfase em História da Educação. Atualmente trabalha como professora no Ensino Superior no curso de Pedagogia e como coordenadora pedagógica em uma instituição privada de educação básica.

Orcid: https://orcid.org/0000-0001-8502-9782

E-mail: daniellaamarques@smail.com

Elaine Rodrigues: Possui graduação em Pedagogia pela Universidade Estadual de Maringá (1987). Mestrado em Educação pela Universidade Estadual de Maringá (1994). Doutorado em História e Sociedade pela Unesp - Universidade Estadual Paulista - Júlio de Mesquita Filho (2002). Pós-doutorado em História da Educação pela 
MARQUES, D. D. A.; RODRIGUES, E.

Universidade Federal de Uberlândia (2015). Atualmente é Coordenadora do Curso de Pedagogia Presencial e EaD da UniFCV - Centro Universitário Cidade Verde/Maringá.

Orcid: https://orcid.org/0000-0001-5219-5450

E-mail: elaineppeuem@gmail.com

Este periódico utiliza a licença Creative Commons Attribution 3.0, para periódicos de acesso aberto (Open Archives Iniciative - OAI)

Inter-Ação, Goiânia, v.45, n.3, p. 923-939, set./dez. 2020. Disponível em: <http://dx.doi.org/10.5216/ia.v45i3.64518>. 